\title{
Covid-19 and Diabetes: A Complex Bidirectional Relationship
}

\author{
Hermine Muniangi-Muhitu ${ }^{1}$, Elina Akalestou ${ }^{1}$, Victoria Salem ${ }^{2}$, Shivani Misra ${ }^{3}$, \\ Nicholas S. Oliver ${ }^{3}$ and Guy A. Rutter ${ }^{1,4^{*}}$ \\ 1 Section of Cell Biology and Functional Genomics, Division of Diabetes, Endocrinology and Metabolism, Department of \\ Metabolism, Digestion and Reproduction, Imperial College London, London, United Kingdom, 2 Section of Endocrinology, \\ Division of Diabetes, Endocrinology and Metabolism, Department of Metabolism, Digestion and Reproduction, Imperial \\ College London, London, United Kingdom, ${ }^{3}$ Section of Metabolic Medicine, Division of Diabetes, Endocrinology and \\ Metabolism, Department of Metabolism, Digestion and Reproduction, Imperial College London, London, United Kingdom, \\ ${ }^{4}$ Lee Kong Chian School of Medicine, Nan Yang Technological University, Singapore, Singapore
}

Covid-19 is a recently-emerged infectious disease caused by the novel severe acute respiratory syndrome coronavirus SARS-CoV2. SARS-CoV2 differs from previous coronavirus infections (SARS and MERS) due to its high infectivity (reproduction value, $\mathrm{R}_{0}$, typically 2-4) and pre- or asymptomatic transmission, properties that have contributed to the current global Covid-19 pandemic. Identified risk factors for disease severity and death from SARS-Cov2 infection include older age, male sex, diabetes, obesity and hypertension. The reasons for these associations are still largely obscure. Evidence is also emerging that SARS-CoV2 infection exacerbates the underlying pathophysiology of hyperglycemia in people with diabetes. Here, we discuss potential mechanisms through which diabetes may affect the risk of more severe outcomes in Covid-19 and, additionally, how diabetic emergencies and longer term pathology may be aggravated by infection with the virus. We consider roles for the immune system, the observed phenomenon of microangiopathy in severe Covid-19 infection and the potential for direct viral toxicity on metabolically-relevant tissues including pancreatic beta cells and targets of insulin action.

Keywords: diabetes, Covid-19, ketoacidosis, management, microangiopathy

\section{COVID-19 PANDEMIC}

Since its emergence in December 2019 in Wuhan, China, severe acute respiratory syndrome caused by coronavirus 2 (SARS-CoV-2), subsequently called coronavirus disease 19 (Covid-19), has ravaged the world (1) and was declared a pandemic by the World Health Organization (WHO) in March 2020 (2). As of June 15, 2020, 8,014,146 people with Covid-19 have been reported in more than 213 countries and territories, causing more than 436,005 deaths $(3,4)$. SARS-CoV-2 is a beta coronavirus with sequence homologies with SARS-CoV (79\%) and distant similarities (50\%) with Middle East respiratory syndrome coronavirus (MERS-CoV) $(5,6)$. It is highly contagious and transmitted between individuals through aerosolized droplets and contact with infected surfaces (7).

Abbreviations: ACE2, angiotensin-converting enzyme 2; DKA, diabetic ketoacidosis; SARS-CoV2, severe acute respiratory syndrome coronavirus-2; T2D, type 2 diabetes. 
Data published at the beginning of the pandemic showed that Covid-19 can cause significant respiratory morbidity and mortality (8). At $\sim 1 \%$ the mortality rate, or case fatality rate, of Covid-19 is ten times that of seasonal influenza (9-11). Age, male sex, ethnicity and existing health problems are all additional risk factors for in-hospital death from Covid-19, with age being the greatest of these: those over 80 years of age have a $>500$-fold higher probability of death than those under $40(4,12)$. Individuals with comorbidities are more likely to suffer a more severe disease course or die (10). The most common comorbidities with Covid-19 infection are metabolic diseases including diabetes, hypertension, obesity and cardiovascular disease $(9,10,13)$. The mechanisms behind these increased risks remain unclear, and will be discussed in the present review, with a focus on the possibility that direct actions of the virus on disease-relevant tissues outside of the respiratory tract are involved.

Whereas diabetes rates in the U.K are $\sim 4.7 \%, 32 \%$ of those who have died from Covid-19 had type 1 or type 2 diabetes (4). Estimates of diabetes prevalence in those who have died as a result of Covid-19 in other populations range from $20-50 \%$ (14). While obesity is associated with increased risk of a requirement for intensive care or death (15), a recent study from NHS England (16) indicates that below a body mass index (BMI) of 35 (at which point challenges are associated with adequate mechanical ventilation), increased risk is largely ascribed to altered predominance of diabetes and its complications. Similar findings were reported by Goldacre et al. (12).

In a recent study from France on $\sim 1,300$ patients (17) multivariate analysis indicated that BMI, micro- and macrovascular complications were associated with the risk of tracheal intubation or death, whereas no association was apparent for diabetes type or glycated hemoglobin (HbAlc). These apparent differences with the NHS England study may, however, reflect the fact that data on diabetes duration and $\mathrm{HbA1c}$ were available for $\sim 60 \%$ of subjects in the smaller French cohort, which was also limited to patients admitted to hospital, potentially limiting the power to detect an $\mathrm{HbAlc}$ signal.

\section{INTERACTION BETWEEN COVID-19 AND DIABETES, HYPERTENSION, AND OBESITY: EPIDEMIOLOGICAL EVIDENCE}

Since the beginning of the Covid-19 outbreak much energy has been devoted to identifying risk factors for infection and severe outcomes, and understanding their underlying molecular mechanisms. Diabetes (22\%) and cerebrovascular (22\%) disease were identified in numerous studies as the most common distinctive comorbidities $(2,18,19)$. Other retrospective studies (9-11), have revealed that the most frequent comorbidities in people infected with Covid-19 virus were hypertension (24.7\%), followed by diabetes $(21.2 \%)$ and coronary heart disease $(8 \%)$ when these variables are assessed individually. In England, 19\% of people admitted to intensive care with Covid-19 suffered from diabetes, $1 / 3$ of whom died in hospital (4). The risk of serious complications and death from coronavirus disease in diabetic patients with diabetes in the UK population is $50 \%$ higher than that of non-diabetic people (14).

An independent association between $\mathrm{HbA}_{1 \mathrm{C}}$ and Covid-19 death rates was revealed in a recent cohort study based on the British population with type 1 (T1D) or type 2 (T2D) diabetes (4). This rate increased in patients with an $\mathrm{HbA}_{1 \mathrm{C}}>58 \mathrm{mmol} /$ mol, suggesting an association with hyperglycemia. Similar findings were reported by Guo and colleagues $(9,20)$.

Obesity is another comorbidity associated with poor outcomes after Covid-19 infection (21), and is associated with poor ventilation of the base of the lungs decreasing oxygen saturation of the blood (13). Indeed, a recent report from the National Research Center (ICNARC) (22) in the UK demonstrated that out of 196 obese patients (the majority of whom were men over 60 years old) with a BMI $>35 \mathrm{~kg} / \mathrm{m}^{2}$ admitted to intensive care, most (3/4) needed mechanical respiration $2 \mathrm{~h}$ after admission. According to another study published recently in the newspaper "Le Monde", in France, 15\% of overweight or obese adults and $41 \%$ of British obese patients admitted to intensive care, were more likely to contract a SARSCoV-2 infection and to develop severe forms (13). The main factors determining the severity of viral infection in obese patients are hormonal environment, the defective response of the innate and adaptive immune system as well as the sedentary lifestyle $(4,23)$. Luzi et al. (23) suggest that obesity not only increases the risk of infection and complications but also the risk of developing a more virulent viral layer, prolonging the transmission of the virus across the whole population and increasing the overall mortality rate as was the case during the H1N1 pandemic in 2009 (23). In summary, obesity and diabetes increase the duration of the disease, the requirement for intensive organ support, and increased risk of mortality.

Finally, hypertension is further, independent risk factor (though less predictive than those above) $(12,16,24)$ and comorbidity in patients with Covid-19 (25).

\section{ANGIOTENSIN-CONVERTING ENZYME, ACE2: ROLES AND ACTION}

Multiple receptors are involved in SARS-CoV2 binding and uptake into cells, as discussed further below. The role of Angiotensin converting enzyme 2, encoded by the ACE2 gene (26), in infection by coronaviruses including SARS (27) and SARS-Cov2 (28) is now well-established. Indeed, changes in ACE2 expression with age and differences between sexes may contribute to the altered risks of Covid-19 infection (29). Both hypertension and diabetes are often treated with ACE inhibitors $(11,14,30)$ and it has been suggested that altered ACE2 levels resulting from treatment may a contributor to disease severity in Covid-19. In results from Fang et al. (18), patients with diabetes and hypertension who had been treated with ACE inhibitors or angiotensin receptor blockers (ARB) had a high number of ACE2 receptors in the lung, and could therefore be at higher risk of developing severe symptoms, if infected with Covid-19. This 
hypothesis was further examined by Sardu et al. (31) in hospitalized hypertensive patients with Covid-19. Nonetheless, no firm link was established between ACEi/ARB and the prognosis of Covid-19 infection.

In normal physiology, ACE2 plays an essential role in the renin-angiotensin-aldosterone system (RAAS) (26, 32). Activation of the RAAS system takes place during a loss of blood volume, a decrease in blood pressure or when the serum concentration of $\mathrm{Na}^{+}$falls, promoting in juxtaglomerular cells in the kidney to release renin. The latter cleaves angiotensinogen to release angiotensin I (1-10), which is further converted by ACE1 into angiotensin II a potent vasoconstrictor. Angiotensin II is degraded by ACE2, which cleaves angiotensin II to generate Ang (1-7).

Ang (1-7) is specific for AT1Ra (AGTRAP) and Mas receptors, which are associated with vasodilation $(26,32,33)$. Therefore, viral depletion of ACE2 in SARS-CoV2 may reduce vasodilatory tone, contributing to the microangiopathy. Of note, AT1R are present on both pancreatic beta and alpha cells in mice (34) and humans (35). Hence lowered ACE2 levels, and consequently of Ang (1-7), may impact hormone secretion from islets.

Could ACE2 present on beta cells represent a direct target for virus entry, potentially leading to the dysregulation or destruction of these cells, promoting a (potentially irreversible) loss of insulin production? Low but detectable (1-4 reads per kilobase of transcript per million reads, RPKM) levels of ACE2 mRNA are reported in purified human beta cells (35), and ACE2 immunoreactivity has also been described on these cells (36). However, the selectivity of the antibodies used in the latter study was not tested directly, and ACE2-mediated SARS-CoV2 entry into beta cells entry remains unproven.

Might elevated levels of ACE2, facilitating viral entry, contribute to increased disease risk and mortality in metabolic disease? In vitro and in vivo studies in disease settings have indicated that ACE2 expression is increased in heart failure, systemic and pulmonary hypertension and diabetes mellitus (33). ACE2 is expressed in several tissues and organs (Table 1). These include endothelial cells as well as vascular smooth muscle cells (26). In the kidney, ACE2 is expressed on the apical surface on the proximal tubules and glomerulus. Its expression has also been observed in the gastrointestinal tract (42). ACE2 has also been reported in the central nervous system and in glial cells $(37,38)$, and SARS-CoV2 infection via the receptor may contribute to the loss of smell (anosmia) observed in many patients (https://covid.joinzoe.com/post/uk-anosmia-covid). Whether ACE2 is expressed by olfactory neurons remains to be demonstrated. ACE2 levels throughout the rest of the human brain appear to be low (42). Finally, thyroid tissue has been shown to express high levels of ACE2 (43). To date, there is limited information regarding the risk of SARS-CoV2 infection in patients with thyroid disease. However, some knowledge regarding an impact of SARS-CoV2 on thyroid function can be inferred from the severe acute respiratory syndrome (SARS) epidemic, when a decrease in serum levels of hormones triiodothyronine (T3) and thyroxines (T4) had been observed in infected patients (44).

\section{SARS-COV-2 AND THE IMMUNE SYSTEM IN DIABETES}

As discussed below, infection with SARS-CoV2 appears to have actions on both immune cells and on endothelial cells pertinent to its interactions with metabolic disease $(23,45)$.

Infection of individual cells with the virus begins with the cleavage of the Spike protein (S), a surface glycoprotein carried by the spicules, in 2 subunits $S 1$ and $S 2$. The S1 subunit of the Spike protein binds to the N-terminal region of ACE2 (33). The second subunit, S2, then interacts with the transmarine protease assisted with serine 2 (TMPRSS2) which cleaves Protein S to allow viral entry (46). RNA from the viral genome is then released into the cytoplasm, allowing viral replication (47) (Figure 1). Thereafter, the virus' genomic RNA, together with the envelope glycoprotein and nucleocapsid protein, form vesicles containing virions via the cell's secretory pathway, which go on to fuse with the plasma membrane and release the virus from the host cell $(5,6)$.

Cytokine production is a key element of the inflammatory and immune response to viral infection. After release from the host, the virus is first recognized by the innate immune system via molecular pattern recognition receptors (PRR), such as type C lectin receptors, and the Toll Like Receptor (TLR) NOD receptor. Exposure to virus causes the expression of inflammatory factors by

TABLE 1 | Summary of the various organs/tissues expressing ACE2.

\begin{tabular}{|c|c|c|c|c|}
\hline Organs & Type of cells expressing ACE2 & Impacts in term of risk & Type of Receptors & References \\
\hline Heart & Myocytes & Cardiac failure & ACE2 & Burrell et al. (26) \\
\hline Brain & Glial cells and neurons & Loss of smell, CV stroke, epilepsy & $\begin{array}{l}\text { ACE2 receptors present in the } \\
\text { central nervous system (CNS) }\end{array}$ & Gupta et al. (37), Bittman et al. (38) \\
\hline Liver & Biliary epithelial cells & Proteinuria & ACE2 & Sun et al. (39) \\
\hline Intestine & Enterocytes & / & ACE2 & Ziegler et al. (40) \\
\hline Lungs & Pneumocytes & Respiratory failure & ACE2 & Mourad et al. (33) \\
\hline Pancreas & Beta cells & Decreased insulin production & ACE2 & Luzi et al. (23), Yang et al. (36) \\
\hline Kidney & Nephron proximal bypass tube cell & Renal failure & ACE2 & Burrell et al. (26) \\
\hline Adipose tissue & Adipocytes & Severe obesity & ACE2 & Shoemaker et al. (41) \\
\hline
\end{tabular}

The third column highlights the failures that the various organs will undergo when the virus binds to the ACE2 receptors present in the different types of cells expressing the angiotensin 2 converting enzyme. 


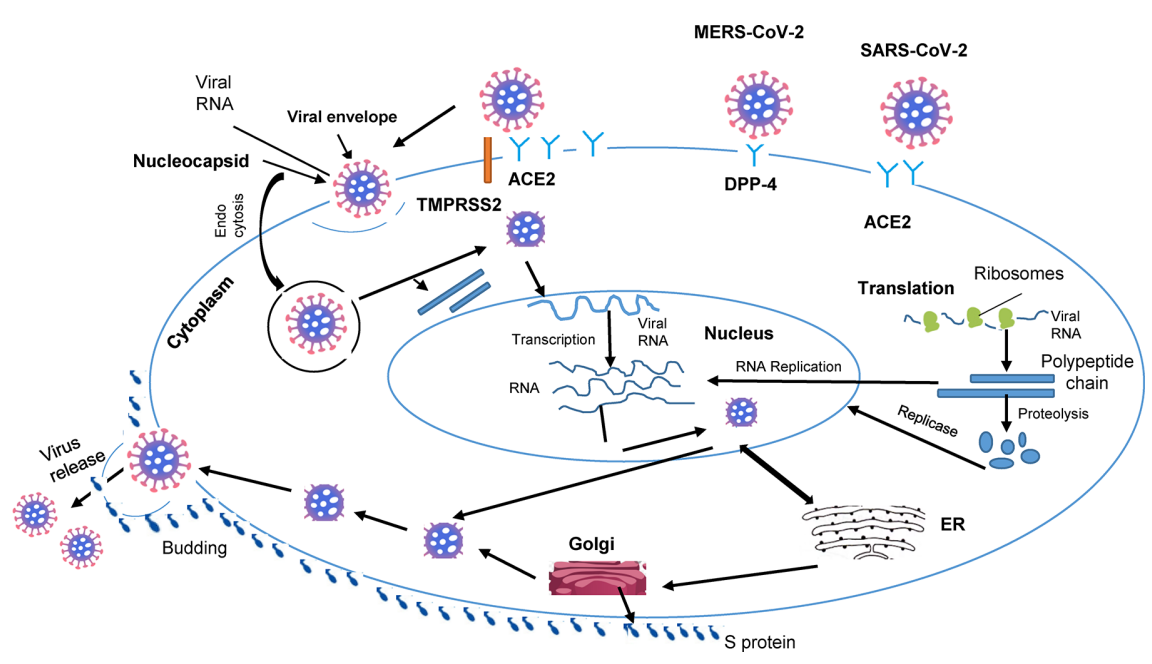

FIGURE 1 | Cellular pathogenesis of coronavirus infection. The lipid envelope (viral) includes spike glycoprotein binding to receptors (ACE2) on the surface of the host. The, entry of cell by endocytosis followed by membrane fusion and release of the virion into the cytosol. Entry of viral RNA into the nucleus and production of new strands of viral RNA and viral proteins. Viral RNA output from the nucleus. Assembly, budding and release of new viruses, impact on organs.

various pathways, in particular the maturation of dendritic cells, and the synthesis of interferons whose role is to limit the spread of the virus and accelerate the phagocytosis of viral antigens (5).

An important feature of Covid-19 infection is a lowered level of lymphocytes in the blood. Implying a similar process after infection with SARS-Cov2, monocytes and $\mathrm{T}$ cells are infected with MERS-CoV via dipeptidyl peptidase 4 (DPP-4), while SARS-CoV infects primary human monocytes as well as dendritic cells (48). This could be due to destruction of these key cells, which might be a contributor to a weakened immune response, facilitating virus proliferation in Covid-19. However, it is important to bear in mind that a failure to observe lymphocytes in the blood might reflect their homing or recruitment to other infected organs such as the lung (49).

The binding of the virus to immune cells also leads to the synthesis of interleukin 6 (IL-6) which, in turn, leads to signaling both in cis and in trans. In cis signaling, IL-6 binds to lymphocytes via cognate receptors. The overproduction of these cytokines (in a "cytokine storm") leads to the risk of multiorganic lesions (35) this might be the main cause of morbidity in subjects with Covid-19. On the other hand, in trans signaling, IL-6 binds to receptors on endothelial cells and may lead to hyper-coagulation, an important risk factor for pulmonary embolism and death (50). The fact that patients with severe forms of SARS-CoV-2 infection express higher than normal plasma concentrations of IL-6 (7) which prompted Mehta and colleagues (51) to propose that secondary hemaphagocytic lymphoistiocytosis (sHLH), characterized by an overproduction of cytokines and expansion of macrophages, is found in severe cases of Covid-19 since the main target cells of SARS-CoV-2 are alveolar macrophages expressing ACE2. A recent clinical trial (52) with Kevzara (Sarilumab), an IL-6 receptor antibody, has, however given mixed results, with positive effects observed in "critical" cases but negative in "severe" cases.

\section{COVID-19 AND THROMBOTIC MICROANGIOPATHY}

Microangiopathy involves damage to smallest blood vessels and can be the result of the formation of small blood clots, termed thrombotic microangiopathy (TMA) that contribute to renal and neuronal pathology (53). A preexisting microangiopathic disease burden (and markers thereof, e.g. poor glycaemic control and duration of diabetes) are strong risk factors for disease severity (54). TMA is reported as a frequent event in Covid-19 and is likely to involve endothelium-mediated complement activation (55). Given high levels of expression of ACE2 in endothelial cells and podocytes, activation of this process may present a unifying mechanism for viral action in a range of susceptible tissues, including kidney and heart. Clinical observations (56) suggest that SARS-CoV-2 infection facilitates the induction of endotheliitis in several organs as a direct consequence of viral infection. This could contribute markedly to life-threatening complications, such as venous thromboembolic disease and multiple organ failure. Complement inhibition (57) may thus represent an important therapeutic target. Moreover, the inflammatory effects of cytokines may also result in vascular endothelial cell injury which could result in thrombosis (58). Therefore, it is possible that the socalled Covid-19 Associated Coagulopathy (CAC) may be a result of the increased inflammatory response (59).

\section{COVID-19 AND DIABETES: A VICIOUS CIRCLE?}

Emerging data indicate a bidirectional relationship between T2D and Covid-19 (Figure 2). Firstly, and as described above, preexisting diabetes is a risk factor for poor outcomes and 
death after Covid-19. Several explanations for this association are possible. Of these the impairment, at different levels, of the innate and adaptive immune response is likely to be involved in the poorer ability to fight infection in patients with diabetes, and particularly in those who are obese $(19,23,30)$. People with all forms of diabetes are at increased risk due to defective innate immunity as well as adaptive immunity (14) Severe Covid-19 infection significantly reduces the numbers of natural killer cells, notably $\mathrm{CD}^{+}$and $\mathrm{CD}^{+}$cells, as well as $\mathrm{CD} 4^{+}$as $\mathrm{CD} 8^{+}$ lymphocytes (7). The mechanisms behind these very recent findings are unclear: whether they involve interactions of the virus with beta cells or target tissues for insulin action, or are the result of an indirect effect of an immune response ("cytokine storm"), is unclear (Figure 2).

The association between Covid-19 and hyperglycemia in elderly patients with T2D (60) seems likely to reflect metabolic inflammation and exaggerated cytokine release. Strikingly, recent data suggest that SARS-CoV2 infection can lead to a deterioration in glycemic control, involving both profound insulin resistance (requiring as much as 50-100 $\mathrm{U}$ insulin/h) and impaired insulin secretion, together leading to diabetic ketoacidosis, DKA $(61,62)$. Thus, frequent cases of severe DKA have been observed on admission to hospital of patients with Covid-19 (14) and contribute to mortality and morbidity (9).

With respect to the glycemic deterioration seen in patients with preexisting T2D during Covid-19, a very recent report (63) provides the intriguing observation that $A C E 2$ expression at both the mRNA and protein is increased substantially in human beta cells in response to response to inflammatory cytokines, presumably rendering these cells more susceptible to infection.

\section{TYPE 2 DIABETES MANAGEMENT IN COVID-19}

The appropriate management of Covid-19 in people with T2D has been debated actively during the present pandemic, especially with regards to the range of drugs best suited for glycemic control that may also reduce the risk of infection and attenuate the severity of complications. This discussion is of great importance since early glycaemic control may be an important therapeutic option to reduce the poor outcomes in hyperglycaemic Covid-19 patients (64). As an example, it has been shown recently that Covid-19 infection management with the drug tocilizumab was not optimally achieved during hyperglycaemia in both diabetic and non-diabetic patients. Moreover, preclinical models found an indirect link between ACE2 upregulation and several anti-diabetic drugs (65-68). We discuss here presently used treatments both in the context of diabetic emergencies (such as DKA; see above) and for less acute management of hyperglycemia, where different regimens may be required. Given that a number of treatments are now repurposed as potential therapeutics for Covid-19 (69), the anti-
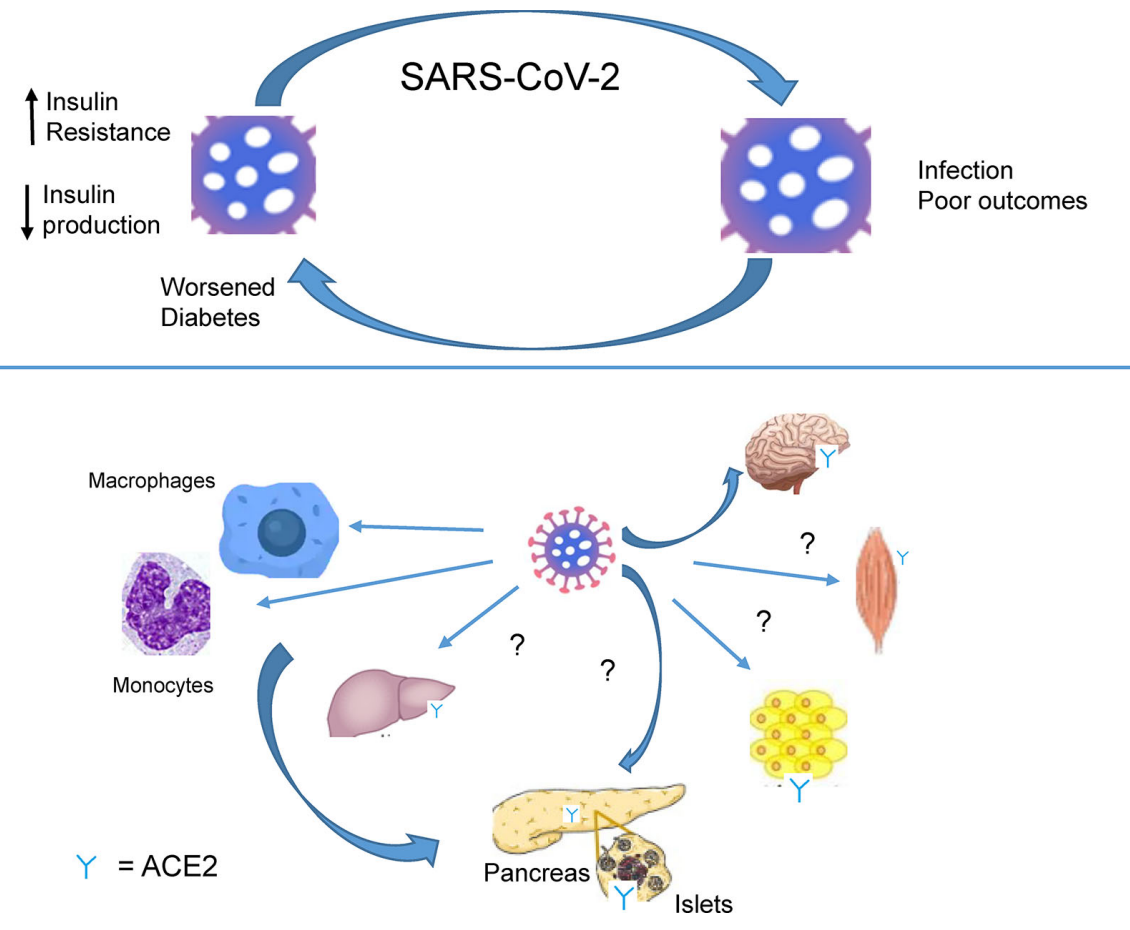

FIGURE 2 | SARS-CoV-2 infection worsens diabetes. Recognition by SAR-CoV-2 of receptors present on immune cells (macrophages, monocytes.) and ACE2 receptors, expressed in several tissues (brain, muscle, adipose tissue, liver, pancreas). Infection causes lowered insulin production and insulin resistance by presently undefined mechanisms. 
inflammatory action of several anti-diabetic drugs may also be explored in this light.

Insulin remains a safe choice under all circumstances and is considered the first-line treatment in hyperglycemic critically-ill patients, and may require very high doses (see above). In patients infected with Covid-19, insulin infusion has been shown to be an effective method for achieving glycemic targets as well as reducing the risk of severe symptoms, when compared to patients that did not receive an infusion (70). It has been shown to modulate inflammatory mediators, suppress toll-like receptors (TLRs) implicated in innate immune responses, and suppress pro-inflammatory transcription factors in mononuclear cells (71). Importantly, insulin reduces activation of the proinflammatory nuclear transcription factor $\kappa B(\mathrm{NF}-\kappa \mathrm{B})$, both in obese non-diabetic and critically ill patients (72, 73). Even though there is no direct link between insulin and ACE2, it has been demonstrated that, in diabetic mice, insulin treatment can attenuate a disintegrin and metalloproteinase-17 (ADAM17) expression in the kidney.

Glucagon-Like Peptide 1 Receptor Agonists (GLP-1RAs) are an important line of pharmaceutical agents that are especially effective in obese people with T2D to address post-prandial hyperglycaemia. Like insulin, they are also exerting antiinflammatory activity, as a growing amount of evidence suggests that they may have beneficial effects on lipid profiles and blood pressure, as well as reduced markers of systemic inflammation and improved endothelial dysfunction $(74,75)$. Specifically in respiratory diseases, GLP-1RAs reduced cytokine concentration and attenuated pulmonary inflammation in preclinical models of lung infection and injury (76-78). Moreover, the GLP-1RA liraglutide has been shown to downregulate immune cell infiltration and protein expression of cytokines, and markedly attenuate NF- $\mathrm{KB}$ activation in a chronic asthma preclinical model $(79,80)$.

Dipeptidyl peptidase 4 (DPP4) inhibitors are often prescribed in combination with other agents for the treatment of T2D. Unlike the majority of anti-diabetic treatments, DPP4 inhibitors do not appear to alter the immune system response in patients with or without T2D (81). However, DPP4 inhibitors have recently been associated with a better clinical outcome in patients with COVID-19 (82) potentially due to the fact that DPP4 is a predicted coronavirus receptor (83). Further details on DPP4 molecular mechanisms and clinical importance have recently been reviewed (20).

Metformin is an oral hypoglycemic agent which is widely used as first-line therapy for T2D as it suppresses hepatic glucose production and increases muscle glucose uptake (84). Similarly to insulin and GLP-1RA, metformin has been suggested to improve chronic inflammation indirectly, via insulin resistance and hyperglycemia improvement, but also directly by inhibiting NF- $\mathrm{KB}$ via AMP-activated protein kinase (AMPK)-dependent and independent pathways (85-88). Another suggested mechanism of the anti-inflammatory action of metformin is inhibition of advanced glycation end products (AGEs) formation, which promote inflammation and glycoxidation (89). However, metformin is not indicated for use in critically- ill hospitalized patients, especially if their hepatic function is impaired, and in cases of dehydration: lactic acidosis is a risk in these circumstances (14). Although concerns have been raised over the use of the anti-rheumatic drug chloroquine or hydroxychloroquine as a potential Covid-19 therapeutic based on studies in animals (90), these were, until recently, used safely together with metformin in humans: however, the licensing of chloroquine use in Covid-19 has recently been withdrawn by the FDA.

Thiazolidinediones are a class of T2D drugs which includes the oral agent pioglitazone. Pioglitazone improves insulin sensitivity through its action at peroxisome proliferatoractivated receptor $\gamma 1$ (PPAR $\gamma 1)$ and PPAR $\gamma$, and affects lipid metabolism through action at PPAR $\alpha$ (91). Although potentially indirect, pioglitazone has been proven to reduce monocyte gene and protein expression of cytokines in patients with impaired glucose tolerance (92). Of note, pioglitazone was found to reduce lung injury by controlling adipose inflammation in a cecal ligation puncture model in mice (93) as well as exert a direct effect on lung inflammation and fibrosis (94). As a result, it has been hypothesized that it should be considered among the drugs currently used against COVID-19 (95). However, use of this drug class in Covid-19 patients is presently very limited.

An additional class of anti-diabetic medications associated with lowering inflammation are the glifozins, or SGLT2 (sodiumglucose cotransporter-2/SLC5A2) inhibitors, which attenuate reabsorption of glucose in the kidney to lower blood sugar. So far, this reported anti-inflammatory effect focuses on the kidney, cardiovascular system and pancreas, rather than lungs $(96,97)$, though it has been shown to indirectly reduce pulmonary infection in diabetic mice (98). Although SGLT2 inhibitors are associated with dehydration and anorexia and therefore may pose a risk for critically ill patients, a new study focusing on hospitalized adult patients with Covid-19 commenced in April 2020 , with the aim of understanding the substantial cardio- and nephroprotective effects of SLGT2 inhibitors in reducing disease progression, complications, and all-cause mortality (99). Recent U.K. guidelines (100) have, nonetheless, advised suspending the use of SGLT2 inhibitors in people with Covid-19 due to the risk of euglycaemic ketoacidosis.

It is important to note that many of the therapeutics mentioned, such as GLP-1RA and SGLT2 inhibitors, have also been strongly associated with improved cardiovascular outcomes $(9,31,34)$. This may be of great importance, as growing evidence links Covid-19 with cardiovascular complications (35), in addition to respiratory disease, especially since SARS-CoV-2 can directly infect engineered human blood vessel organoids (36).

Overall, most anti-diabetic therapeutics demonstrate anti-inflammatory effects (Figure 3), either indirectly by improving insulin resistance or directly by down-regulating proinflammatory pathways such as those involving nuclear factor $\kappa \mathrm{B}(\mathrm{NF}-\mathrm{\kappa B})$. Moreover, several drugs have been shown to act directly on the lungs and have a pulmonary effect in respiratory infection and injury. However, most of the studies reporting this utilized preclinical models. It will therefore be 


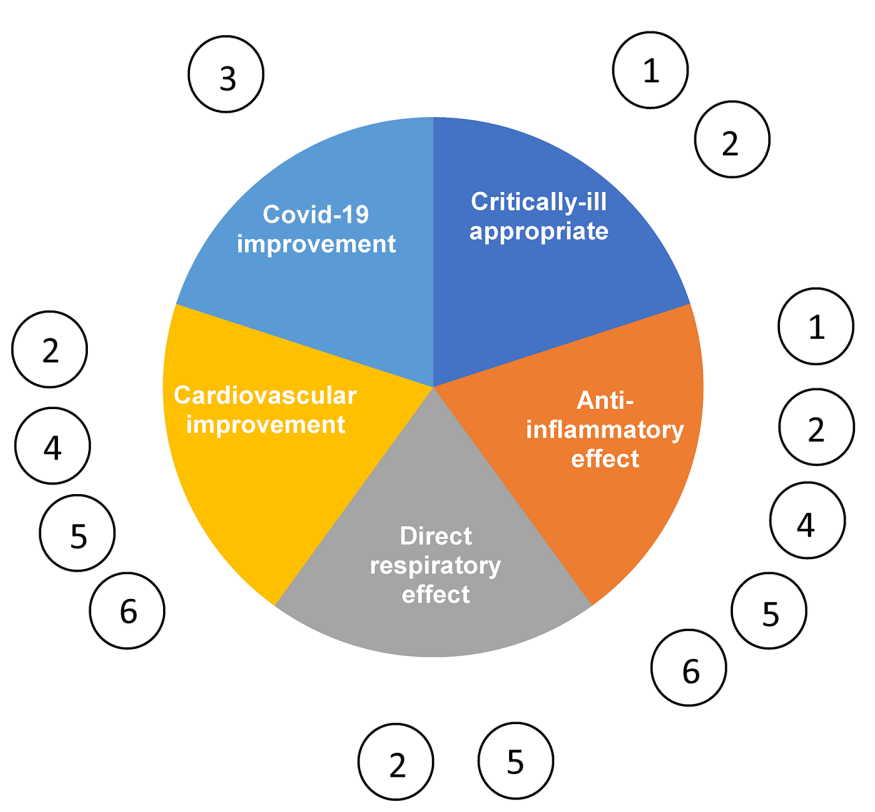

1. Insulin

2. GLP-1RA

3. DPP4i

4. Metformin

5. Pioglitazone

6. SGLT2i

FIGURE 3 | Type 2 diabetes management therapeutics in Covid-19. The six main classes of glucose-lowering drugs summarized according to their reported effect on inflammation, cardiovascular disease, respiratory disease and critically ill patient safety.

important to validate these findings clinically in the context of experimental coronavirus infection in order to determine which anti-diabetic treatments are optimal for a combined management of T2D and Covid-19.

\section{CONCLUSIONS AND PERSPECTIVES}

There is now considerable evidence that diabetes is both a risk factor for, and a condition worsened by, SARS-CoV-2 infection. Whereas weakened immunity, alongside impaired kidney function - both features of both aging and diabetes - likely drive the former, exaggerated immune responses probably underlie the latter. Further research will be needed to answer these closely interlinked questions, and we provide suggestions for prioritization below.

With respect to heightened susceptibility to poor Covid-19 outcomes in people with diabetes, key questions include the role of the endothelium and blood hyper-coagulation. Could this affect islet or kidney function? Most evidence suggests that levels of the relevant SARS-Cov2 receptors (ACE2 and DPP4) are low, but not zero, in these tissues - DPP4 is detectable in islets, liver and kidney - suggesting that immune cell-mediated effects are the more likely. More detailed and robust assessment of the expression at the protein level, and sub-cellular localization, of these receptors in the above tissues, and their susceptibility to SARS-Cov2 infection in vitro and in vivo, are needed.

Regarding the effects of viral infection on glucose control: there is as yet little evidence to suggest that deteriorating glycemia and metabolic control in patients with diabetes outlasts infection, suggesting that immune-mediated destruction of pancreatic beta cells akin to Type 1 diabetes is unlikely to be involved. Nevertheless, formal analysis of this question, i.e. epidemiological assessment of the reversion of glycemic symptoms post Covid-19, as well as histological quantitation post mortem of beta cell numbers, and islet infiltration with immune cells, are now called for. The most question remains: are the effects of the virus on glycemic control purely the result of an over-active immune system, with immune cells and inflammatory cytokines acting on multiple tissues (which)?, or are there direct actions of the virus on tissues and organs relevant to metabolic homoeostasis (beta cells, other islet hormone-secreting cells, liver, fat, muscle, brain, kidney etc.)? Studies in animal models overexpressing or inactivated for ACE2 (101) or other SARS-CoV2 receptors may be informative here. Where feasible, more in-depth physiological studies (e.g. glucose tolerance tests, hyperinsulimic or hyperglycemic clamps) are required in patients to assess insulin sensitivity (102) and beta cell glucose responsiveness (103) with greater precision. Followup studies will then be required at the cellular level to understand the molecular mechanisms behind altered beta (or other) cell function or insulin action, and to understand whether, and through what membrane trafficking pathways, viral replication and shedding occurs in these cell types. Finally, clinical trials in man, informed by the results of the above, will be needed to determine which of the existing, and potentially new, treatments, are likely to be efficacious in reducing glycemia-related medical emergencies as well as the more severe manifestations of Covid-19. 


\section{AUTHOR CONTRIBUTIONS}

GR, HM-M, and EA prepared the figures. All authors contributed to the article and approved the submitted version.

\section{FUNDING}

GR was supported by a Wellcome Trust Investigator Award (212625/Z/18/Z), MRC Programme grants (MR/R022259/1,

\section{REFERENCES}

1. Andersen KG, Rambaut A, Lipkin WI, Holmes EC, Garry RF. The proximal origin of SARS-CoV-2. Nat Med (2020) 26:450-2. doi: 10.1038/s41591-0200820-9

2. Pal R, Bhansali A. COVID-19, diabetes mellitus and ACE2: The conundrum. Diabetes Res Clin Pract (2020) 162:108132. doi: 10.1016/j.diabres.2020. 108132

3. Worldometer. - real time world statistics. Worldometer. Available at: http:// www.worldometers.info/ (Accessed June 7, 2020).

4. Barron E, Bakhai C, Kar P, Weaver A, Bradley D, Ismail H, et al. Associations of type 1 and type 2 diabetes with COVID-19-related mortality in England: a whole-population study. Lancet Diabetes Endocrinol 8(10):813-22. doi: 10.1016/ S2213-8587(20)30272-2.

5. Yi Y, Lagniton PNP, Ye S, Li E, Xu R-H. COVID-19: what has been learned and to be learned about the novel coronavirus disease. Int J Biol Sci (2020) 16:1753-66. doi: 10.7150/ijbs.45134

6. Neurath MF. COVID-19 and immunomodulation in IBD. Gut (2020) 69:1335-42. doi: 10.1136/gutjnl-2020-321269

7. Zhong J, Tang J, Ye C, Dong L. The immunology of COVID-19: is immune modulation an option for treatment? Lancet Rheumatol (2020). doi: 10.1016/S2665-9913(20)30120-X

8. Zhu N, Zhang D, Wang W, Li X, Yang B, Song J, et al. A Novel Coronavirus from Patients with Pneumonia in China, 2019. N Engl J Med (2020) 382:727-33. doi: 10.1056/NEJMoa2001017

9. Guo W, Li M, Dong Y, Zhou H, Zhang Z, Tian C, et al. Diabetes is a risk factor for the progression and prognosis of COVID-19. Diabetes Metab Res $\operatorname{Rev}(2020)$. doi: 10.1002/dmrr.3319

10. Guan W, Liang W, Zhao Y, Liang H, Chen Z, Li Y, et al. Comorbidity and its impact on 1590 patients with Covid-19 in China: A Nationwide Analysis. Eur Respir J (2020) 55(5):2000547. doi: 10.1183/13993003.005472020

11. Zhou F, Yu T, Du R, Fan G, Liu Y, Liu Z, et al. Clinical course and risk factors for mortality of adult inpatients with COVID-19 in Wuhan, China: a retrospective cohort study. Lancet (2020) 395:1054-62. doi: 10.1016/ S0140-6736(20)30566-3

12. Williamson EJ, Walker AJ, Bhaskaran K, Bacon S, Bates C, Morton CE, et al. Factors associated with COVID-19-related death using OpenSAFELY. Nature (2020) 584:430-6. doi: 10.1038/s41586-020-2521-4

13. Simonnet A, Chetboun M, Poissy J, Raverdy V, Noulette J, Duhamel A, et al. High prevalence of obesity in severe acute respiratory syndrome coronavirus-2 (SARS-CoV-2) requiring invasive mechanical ventilation. Obesity (2020) 1195-9. doi: 10.1002/oby.22831

14. Bornstein SR, Rubino F, Khunti K, Mingrone G, Hopkins D, Birkenfeld AL, et al. Practical recommendations for the management of diabetes in patients with COVID-19. Lancet Diabetes Endocrinol (2020) 546-50. doi: 10.1016/ S2213-8587(20)30152-2

15. Caussy C, Pattou F, Wallet F, Simon C, Chalopin S, Telliam C, et al. Prevalence of obesity among adult inpatients with COVID-19 in France. Lancet Diabetes Endocrinol (2020) 30160-1. doi: 10.1016/S2213-8587(20) 30160-1

16. NHS England. Type 1 and Type 2 diabetes and COVID-19 related mortality in England. Available at: https://www.england.nhs.uk/publication/type-1and-type-2-diabetes-and-covid-19-related-mortality-in-england/ (Accessed June 7,2020$)$
MR/J0003042/1, MR/L020149/1) and by Diabetes UK (BDA/11/ 0004210, BDA/15/0005275, BDA 16/0005485) project grants. VS is the recipient of a Diabetes UK Harry Keen Clinician Scientist Fellowship. This project has received funding from the European Union's Horizon 2020 research and innovation programme via the Innovative Medicines Initiative 2 Joint Undertaking under grant agreement No 115881 (RHAPSODY). This Joint Undertaking receives support from the European Union's Horizon 2020 research and innovation programme and EFPIA.

17. Cariou B, Hadjadj S, Wargny M, Pichelin M, Al-Salameh A, Allix I, et al. Phenotypic characteristics and prognosis of inpatients with COVID-19 and diabetes: the CORONADO study. Diabetologia (2020) 63(8):1500-15. doi: $10.1007 / \mathrm{s} 00125-020-05180-\mathrm{x}$

18. Fang L, Karakiulakis G, Roth M. Are patients with hypertension and diabetes mellitus at increased risk for COVID-19 infection? Lancet Respir Med (2020) 8:e21. doi: 10.1016/S2213-2600(20)30116-8

19. COVID-19 Infection in People with Diabetes. touchENDOCRINOLOGY Available at: https://www.touchendocrinology.com/insight/covid-19infection-in-people-with-diabetes/ (Accessed April 29, 2020).

20. Drucker DJ. Coronavirus Infections and Type 2 Diabetes-Shared Pathways with Therapeutic Implications. Endocr Rev (2020) 41:457-70. doi: 10.1210/ endrev/bnaa011

21. Obesity Link to Severe COVID-19, Especially in the Under 60s. Medscape. Available at: http://www.medscape.com/viewarticle/928836 (Accessed May $4,2020)$

22. Early study into UK Covid-19 critical care points to risk factors. Pulse Today Available at: http://www.pulsetoday.co.uk/clinical/clinical-specialties/ respiratory-/early-study-into-uk-covid-19-critical-care-points-to-riskfactors/20040459.article (Accessed May 14, 2020).

23. Luzi L, Radaelli MG. Influenza and obesity: its odd relationship and the lessons for COVID-19 pandemic. Acta Diabetol (2020) 57(6):759-64. doi: 10.1007/s00592-020-01522-8

24. Huang C, Wang Y, Li X, Ren L, Zhao J, Hu Y, et al. Clinical features of patients infected with 2019 novel coronavirus in Wuhan, China. Lancet Lond Engl (2020) 395:497-506. doi: 10.1016/S0140-6736(20)30183-5

25. Schiffrin EL, Flack JM, Ito S, Muntner P, Webb RC. Hypertension and COVID-19. Am J Hypertens (2020) 33:373-4. doi: 10.1093/ajh/hpaa057

26. Burrell LM, Johnston CI, Tikellis C, Cooper ME. ACE2, a new regulator of the renin-angiotensin system. Trends Endocrinol Metab (2004) 15:166-9. doi: 10.1016/j.tem.2004.03.001

27. Li W, Moore MJ, Vasilieva N, Sui J, Wong SK, Berne MA, et al. Angiotensinconverting enzyme 2 is a functional receptor for the SARS coronavirus. Nature (2003) 426:450-4. doi: 10.1038/nature02145

28. Zhou P, Yang X-L, Wang X-G, Hu B, Zhang L, Zhang W, et al. A pneumonia outbreak associated with a new coronavirus of probable bat origin. Nature (2020) 579:270-3. doi: 10.1038/s41586-020-2012-7

29. Li Y, Zhou W, Yang L, You R. Physiological and pathological regulation of ACE2, the SARS-CoV-2 receptor. Pharmacol Res (2020) 157:104833. doi: 10.1016/j.phrs.2020.104833

30. Stefan N, Birkenfeld AL, Schulze MB, Ludwig DS. Obesity and impaired metabolic health in patients with COVID-19. Nat Rev Endocrinol (2020) 16:341-2. doi: 10.1038/s41574-020-0364-6

31. Sardu C, Maggi P, Messina V, Iuliano P, Sardu A, Iovinella V, et al. Could anti-hypertensive drug therapy affect the clinical prognosis of hypertensive patients with COVID-19 infection? Data from centers of southern Italy. J Am Heart Assoc (2020) 0:e016948. doi: 10.1161/JAHA.120.016948

32. Batlle D, Soler MJ, Ye M. ACE2 and Diabetes: ACE of ACEs? Diabetes (2010) 59:2994-6. doi: 10.2337/db10-1205

33. Mourad J-J, Levy BI. Interaction between RAAS inhibitors and ACE2 in the context of COVID-19. Nat Rev Cardiol (2020) 17:313-3. doi: 10.1038/ s41569-020-0368-x

34. Benner C, van der Meulen T, Cacéres E, Tigyi K, Donaldson CJ, Huising MO. The transcriptional landscape of mouse beta cells compared to human beta cells reveals notable species differences in long non-coding RNA and 
protein-coding gene expression. BMC Genomics (2014) 15:620. doi: 10.1186/ 1471-2164-15-620

35. Blodgett DM, Nowosielska A, Afik S, Pechhold S, Cura AJ, Kennedy NJ, et al. Novel Observations From Next-Generation RNA Sequencing of Highly Purified Human Adult and Fetal Islet Cell Subsets. Diabetes (2015) 64:3172-81. doi: 10.2337/db15-0039

36. Yang J-K, Lin S-S, Ji X-J, Guo L-M. Binding of SARS coronavirus to its receptor damages islets and causes acute diabetes. Acta Diabetol (2010) 47:193-9. doi: 10.1007/s00592-009-0109-4

37. How COVID-19 Affects the Brain. Medscape. Available at: http://www. medscape.com/viewarticle/928903 (Accessed May 14, 2020).

38. COVID 19 Expression Of ACE2 Receptors In The Brain Suggest Neurotropic Damage. MaplesPub. Available at: https://www.maplespub.com/article/ COVID-19-Expression-of-ACE2-receptors-in-the-Brain-SuggestNeurotropic-Damage\#article_tab (Accessed May 14, 2020).

39. Sun J, Aghemo A, Forner A, Valenti L. COVID-19 and liver disease. Liver Int (2020) 40(6):1278-81. doi: 10.1111/liv.14470 n/a.

40. Ziegler CGK, Allon SJ, Nyquist SK, Mbano IM, Miao VN, Tzouanas CN, et al. SARS-CoV-2 receptor ACE2 is an interferon-stimulated gene in human airway epithelial cells and is detected in specific cell subsets across tissues. Cell (2020) 181(5):1016-35.e19. doi: 10.1016/j.cell.2020.04.035

41. Shoemaker R, Tannock LR, Su W, Gong M, Gurley SB, Thatcher SE, et al. Adipocyte deficiency of ACE2 increases systolic blood pressures of obese female C57BL/6 mice. Biol Sex Differ (2019) 10:45. doi: 10.1186/s13293-019-0260-8

42. BioGPS. - your Gene Portal System. Available at: http://biogps.org/\#goto= welcome (Accessed June 8, 2020).

43. Li M-Y, Li L, Zhang Y, Wang X-S. Expression of the SARS-CoV-2 cell receptor gene ACE2 in a wide variety of human tissues. Infect Dis Poverty (2020) 9:45. doi: 10.1186/s40249-020-00662-x

44. Guo Y, Korteweg C, McNutt MA, Gu J. Pathogenetic mechanisms of severe acute respiratory syndrome. Virus Res (2007) 133:4-12. doi: 10.1016/ j.virusres.2007.01.022

45. Gheblawi M, Wang K, Viveiros A, Nguyen Q, Zhong J-C, Turner AJ, et al. Angiotensin-Converting Enzyme 2: SARS-CoV-2 Receptor and Regulator of the Renin-Angiotensin System. Circ Res (2020) 126:1456-74. doi: 10.1161/ CIRCRESAHA.120.317015

46. Hoffmann M, Kleine-Weber H, Schroeder S, Krüger N, Herrler T, Erichsen S, et al. SARS-CoV-2 Cell Entry Depends on ACE2 and TMPRSS2 and Is Blocked by a Clinically Proven Protease Inhibitor. Cell (2020) 181:271-80. doi: 10.1016/j.cell.2020.02.052

47. Wadman M, Couzin-Frankel J, Kaiser J, Matacic C. How does coronavirus kill? Clinicians trace a ferocious rampage through the body, from brain to toes (2020). Sci AAAS. Available at: https://www.sciencemag.org/news/2020/04/ how-does-coronavirus-kill-clinicians-trace-ferocious-rampage-throughbody-brain-toes (Accessed April 29, 2020).

48. Moore JB, June CH. Cytokine release syndrome in severe COVID-19. Science (2020) 368:473-4. doi: 10.1126/science.abb8925

49. Xu Z, Shi L, Wang Y, Zhang J, Huang L, Zhang C, et al. Pathological findings of COVID-19 associated with acute respiratory distress syndrome. Lancet Respir Med (2020) 8:420-2. doi: 10.1016/S2213-2600(20)30076-X

50. Jose RJ, Manuel A. COVID-19 cytokine storm: the interplay between inflammation and coagulation. Lancet Respir Med (2020) 30216-2. doi: 10.1016/S2213-2600(20)30216-2

51. Mehta P, McAuley DF, Brown M, Sanchez E, Tattersall RS, Manson JJ. COVID19: consider cytokine storm syndromes and immunosuppression. Lancet (2020) 395:1033-4. doi: 10.1016/S0140-6736(20)30628-0

52. Sanofi. Press Releases, Monday, April 27, 2020. HttpswwwsanoficomenmediaRoompress-Releases20202020-04-27-12-58-00. Available at: https://www.sanofi. com/media-room/press-releases/2020/2020-04-27 (Accessed June 15, 2020). 12-58-00 2022288.

53. Benz K, Amann K. Thrombotic microangiopathy: new insights. Curr Opin Nephrol Hypertens (2010) 19:242-7. doi: 10.1097/MNH.0b013e3283378f25

54. Sharma S, Schaper D, Rayman G. Microangiopathy: Is it relevant to wound healing in diabetic foot disease? Diabetes Metab Res Rev (2020) 36 Suppl 1: e3244. doi: 10.1002/dmrr.3244

55. Gavriilaki E, Brodsky RA. Severe COVID-19 infection and thrombotic microangiopathy: success does not come easily. Br J Haematol (2020) e227-30. doi: 10.1111/bjh.16783
56. Varga Z, Flammer AJ, Steiger P, Haberecker M, Andermatt R, Zinkernagel AS, et al. Endothelial cell infection and endotheliitis in COVID-19. Lancet (2020) 395:1417-8. doi: 10.1016/S0140-6736(20)30937-5

57. Campbell Courtney M. Kahwash Rami. Will Complement Inhibition Be the New Target in Treating COVID-19-Related Systemic Thrombosis? Circulation (2020) 141:1739-41. doi: 10.1161/CIRCULATIONAHA.120.047419

58. Leisman DE, Deutschman CS, Legrand M. Facing COVID-19 in the ICU: vascular dysfunction, thrombosis, and dysregulated inflammation. Intensive Care Med (2020) 46:1105-8. doi: 10.1007/s00134-020-06059-6

59. Becker RC. COVID-19 update: Covid-19-associated coagulopathy. J Thromb Thrombolysis (2020) 50:54-67. doi: 10.1007/s11239-020-02134-3

60. Xue T, Li Q, Zhang Q, Lin W, Wen J, Li L, et al. Blood glucose levels in elderly subjects with type 2 diabetes during COVID-19 outbreak: a retrospective study in a single center. medRxiv (2020). doi: 10.1101/ 2020.03.31.20048579

61. Rayman G, Lumb A, Kennon B, Cottrell C, Nagi D, Page E, et al. Guidance on the management of Diabetic Ketoacidosis in the exceptional circumstances of the COVID-19 pandemic. Diabetes Med (2020) 37(7):1214-16. doi: 10.1111/ dme. $14328 \mathrm{n} / \mathrm{a}$.

62. ADA. How COVID-19 Impacts People with Diabetes. Available at: https:// www.diabetes.org/coronavirus-covid-19/how-coronavirus-impacts-peoplewith-diabetes (Accessed April 29, 2020).

63. Fignani D, Licata G, Brusco N, Nigi L, Grieco GE, Marselli L, et al. SARSCoV-2 receptor Angiotensin I-Converting Enzyme type 2 is expressed in human pancreatic islet $\beta$-cells and is upregulated by inflammatory stress. bioRxiv (2020). doi: 10.1101/2020.07.23.208041 2020.07.23.208041.

64. Sardu C, D’Onofrio N, Balestrieri ML, Barbieri M, Rizzo MR, Messina V, et al. Hyperglycaemia on admission to hospital and COVID-19. Diabetologia (2020). doi: 10.1007/s00125-020-05216-2

65. Tripathy D, Daniele G, Fiorentino TV, Perez-Cadena Z, Chavez-Velasquez A, Kamath S, et al. Pioglitazone improves glucose metabolism and modulates skeletal muscle TIMP-3-TACE dyad in type 2 diabetes mellitus: a randomised, double-blind, placebo-controlled, mechanistic study. Diabetologia (2013) 56:2153-63. doi: 10.1007/s00125-013-2976-Z

66. Salem ESB, Grobe N, Elased K. Insulin treatment attenuates renal ADAM17 and ACE2 shedding in diabetic Akita mice. Am J Physiol Renal Physiol (2014) 306:F629-39. doi: 10.1152/ajprenal.00516.2013

67. Romaní-Pérez M, Outeiriño-Iglesias V, Moya CM, Santisteban P, GonzálezMatías LC, Vigo E, et al. Activation of the GLP-1 Receptor by Liraglutide Increases ACE2 Expression, Reversing Right Ventricle Hypertrophy, and Improving the Production of SP-A and SP-B in the Lungs of Type 1 Diabetes Rats. Endocrinology (2015) 156:3559-69. doi: 10.1210/en.2014-1685

68. Dambha-Miller H, Albasri A, Hodgson S, Wilcox CR, Khan S, Islam NN, et al. Currently prescribed drugs in the UK that could up or downregulate ACE2 in COVID-19 disease: A systematic review. medRxiv (2020). doi: $10.1101 / 2020.05 .19 .20106856$

69. Johnson RM, Vinetz JM. Dexamethasone in the management of covid -19. BMJ (2020) 370:2648. doi: 10.1136/bmj.m2648

70. Sardu C, D’Onofrio N, Balestrieri ML, Barbieri M, Rizzo MR, Messina V, et al. Outcomes in Patients With Hyperglycemia Affected by COVID-19: Can We Do More on Glycemic Control? Diabetes Care (2020) 43:1408-15. doi: $10.2337 / \mathrm{dc} 20-0723$

71. Sun Q, Li J, Gao F. New insights into insulin: The anti-inflammatory effect and its clinical relevance. World J Diabetes (2014) 5:89-96. doi: 10.4239/wjd.v5.i2.89

72. Dandona P, Aljada A, Mohanty P, Ghanim H, Hamouda W, Assian E, et al. Insulin inhibits intranuclear nuclear factor kappaB and stimulates IkappaB in mononuclear cells in obese subjects: evidence for an anti-inflammatory effect? J Clin Endocrinol Metab (2001) 86:3257-65. doi: 10.1210/jcem.86.7.7623

73. Ma C, Liu W, Cui Q, Gu C, Dou Y, Zhao R, et al. [Effects of intensive insulin therapy on plasma nitric oxide and endothelin-1 levels in patients undergoing cardiac surgery under cardiopulmonary bypass]. Zhonghua Wai Ke Za Zhi (2008) 46:443-5. doi: 10.4330/wjc.v6.i11.1209

74. Lee Y-S, Jun H-S. Anti-Inflammatory Effects of GLP-1-Based Therapies beyond Glucose Control. Mediators Inflammation (2016) 2016:3094642. doi: 10.1155/2016/3094642

75. Rizzo M, Nikolic D, Banach M, Patti AM, Montalto G, Rizvi AA. Incretin-based therapies, glucometabolic health and endovascular inflammation. Curr Pharm Des (2014) 20:4953-60. doi: 10.2174/1381612819666131206102255 
76. Viby N-E, Isidor MS, Buggeskov KB, Poulsen SS, Hansen JB, Kissow H. Glucagon-like peptide-1 (GLP-1) reduces mortality and improves lung function in a model of experimental obstructive lung disease in female mice. Endocrinology (2013) 154:4503-11. doi: 10.1210/en.2013-1666

77. Zhou F, Zhang Y, Chen J, Hu X, Xu Y. Liraglutide attenuates lipopolysaccharide-induced acute lung injury in mice. Eur J Pharmacol (2016) 791:735-40. doi: 10.1016/j.ejphar.2016.10.016

78. Bloodworth MH, Rusznak M, Pfister CC, Zhang J, Bastarache L, Calvillo SA, et al. Glucagon-like peptide 1 receptor signaling attenuates respiratory syncytial virus-induced type 2 responses and immunopathology. J Allergy Clin Immunol (2018) 142:683-7. doi: 10.1016/j.jaci.2018.01.053

79. Gou S, Zhu T, Wang W, Xiao M, Wang X, Chen Z. Glucagon like peptide-1 attenuates bleomycin-induced pulmonary fibrosis, involving the inactivation of NF- $\kappa \mathrm{B}$ in mice. Int Immunopharmacol (2014) 22:498-504. doi: 10.1016/ j.intimp.2014.07.010

80. Zhu T, Wu X-L, Zhang W, Xiao M. Glucagon Like Peptide-1 (GLP-1) Modulates OVA-Induced Airway Inflammation and Mucus Secretion Involving a Protein Kinase A (PKA)-Dependent Nuclear Factor- $\kappa \mathrm{B}$ (NFкB) Signaling Pathway in Mice. Int J Mol Sci (2015) 16:20195-211. doi: 10.3390/ijms160920195

81. Poppel PCM, van, Gresnigt MS, Smits P, Netea MG, Tack CJ. The dipeptidyl peptidase-4 inhibitor vildagliptin does not affect ex vivo cytokine response and lymphocyte function in patients with type 2 diabetes mellitus. Diabetes Res Clin Pract (2014) 103:395-401. doi: 10.1016/j.diabres.2013.12.039

82. Rhee SY, Lee J, Nam H, Kyoung D-S, Kim DJ. Effects of a DPP-4 inhibitor and RAS blockade on clinical outcomes of patients with diabetes and COVID-19. medRxiv (2020). doi: 10.1101/2020.05.20.20108555 2020.05.20.20108555.

83. Li Y, Zhang Z, Yang L, Lian X, Xie Y, Li S, et al. The MERS-CoV Receptor DPP4 as a Candidate Binding Target of the SARS-CoV-2 Spike. iScience (2020) 23(8):101400. doi: 10.1016/j.isci.2020.101400

84. Stumvoll M, Nurjhan N, Perriello G, Dailey G, Gerich JE. Metabolic effects of metformin in non-insulin-dependent diabetes mellitus. N Engl J Med (1995) 333:550-4. doi: 10.1056/NEJM199508313330903

85. Li S-N, Wang X, Zeng Q-T, Feng Y-B, Cheng X, Mao X-B, et al. Metformin inhibits nuclear factor kappaB activation and decreases serum highsensitivity C-reactive protein level in experimental atherogenesis of rabbits. Heart Vessels (2009) 24:446-53. doi: 10.1007/s00380-008-1137-7

86. Hattori Y, Suzuki K, Hattori S, Kasai K. Metformin inhibits cytokineinduced nuclear factor kappaB activation via AMP-activated protein kinase activation in vascular endothelial cells. Hypertens. Dallas Tex 1979 (2006) 47:1183-8. doi: 10.1161/01.HYP.0000221429.94591.72

87. Saisho Y. Metformin and Inflammation: Its Potential Beyond Glucoselowering Effect. Endocr Metab Immune Disord - Drug Targets (2015) 15:196-205. doi: 10.2174/1871530315666150316124019

88. Cameron AR, Morrison VL, Levin D, Mohan M, Forteath C, Beall C, et al. AntiInflammatory Effects of Metformin Irrespective of Diabetes Status. Circ Res (2016) 119:652-65. doi: 10.1161/CIRCRESAHA.116.308445

89. Beisswenger P, Ruggiero-Lopez D. Metformin inhibition of glycation processes. Diabetes Metab (2003) 29:6S95-103. doi: 10.1016/s1262-3636(03)72793-1

90. Zhou L, Xu Z, Castiglione GM, Soiberman US, Eberhart CG, Duh EJ. ACE2 and TMPRSS2 are expressed on the human ocular surface, suggesting susceptibility to SARS-CoV-2 infection. bioRxiv (2020). doi: 10.1101/ 2020.05.09.086165 2020.05.09.086165.

91. Smith U. Pioglitazone: mechanism of action. Int J Clin Pract Suppl (2001) 121:13-8. doi: 10.1049/PBPC003E_ch2

92. Zhang W-Y, Schwartz EA, Permana PA, Reaven PD. Pioglitazone inhibits the expression of inflammatory cytokines from both monocytes and lymphocytes in patients with impaired glucose tolerance. Arterioscler. Thromb Vasc Biol (2008) 28:2312-8. doi: 10.1161/ATVBAHA.108.175687

93. Kutsukake M, Matsutani T, Tamura K, Matsuda A, Kobayashi M, Tachikawa E, et al. Pioglitazone attenuates lung injury by modulating adipose inflammation. J Surg Res (2014) 189:295-303. doi: 10.1016/j.jss.2014.03.007

94. Aoki Y, Maeno T, Aoyagi K, Ueno M, Aoki F, Aoki N, et al. Pioglitazone, a Peroxisome Proliferator-Activated Receptor Gamma Ligand, Suppresses Bleomycin-Induced Acute Lung Injury and Fibrosis. Respiration (2009) 77:311-9. doi: 10.1159/000168676

95. Carboni E, Carta AR, Carboni E. Can pioglitazone be potentially useful therapeutically in treating patients with COVID-19? Med Hypotheses (2020) 140:109776. doi: 10.1016/j.mehy.2020.109776

96. Heerspink HJL, Perco P, Mulder S, Leierer J, Hansen MK, Heinzel A, et al. Canagliflozin reduces inflammation and fibrosis biomarkers: a potential mechanism of action for beneficial effects of SGLT2 inhibitors in diabetic kidney disease. Diabetologia (2019) 62:1154-66. doi: 10.1007/s00125-0194859-4

97. Bonnet F, Scheen AJ. Effects of SGLT2 inhibitors on systemic and tissue lowgrade inflammation: The potential contribution to diabetes complications and cardiovascular disease. Diabetes Metab (2018) 44:457-64. doi: 10.1016/ j.diabet.2018.09.005

98. Åstrand A, Wingren C, Benjamin A, Tregoning JS, Garnett JP, Groves H, et al. Dapagliflozin-lowered blood glucose reduces respiratory Pseudomonas aeruginosa infection in diabetic mice. Br J Pharmacol (2017) 174:836-47. doi: $10.1111 / \mathrm{bph} .13741$

99. Dapagliflozin in Respiratory Failure in Patients With COVID-19 - Full Text View - ClinicalTrials.gov. Available at: https://clinicaltrials.gov/ct2/show/ NCT04350593 (Accessed June 8, 2020).

100. Summary of COVID-19 medicines guidance: Diabetes. SPS - Spec Pharm Serv. Available at: https://www.sps.nhs.uk/articles/summary-of-covid-19medicines-guidance-diabetes/ (Accessed June 15, 2020).

101. Jiang RD, Liu M-Q, Chen Y, Shan C, Zhou Y-W, Shen X-R. Pathogenesis of SARS-CoV-2 in Transgenic Mice Expressing Human AngiotensinConverting Enzyme 2. Cell (2020) 182(1):50-8.e8. doi: 10.1016/ j.cell.2020.05.027

102. Swan JW, Walton C, Godsland IF. Assessment of insulin sensitivity in man: a comparison of minimal model- and euglycaemic clamp-derived measures in health and heart failure. Clin Sci (Lond) (1994) 86(3):317-22. doi: 10.1042/ cs0860317

103. Ferrannini E, Mari A. $\beta$-Cell function in type 2 diabetes. Metabolism (2014) 63(10):1217-27. doi: 10.1016/j.metabol.2014.05.012

Conflict of Interest: GR has received research funding in the past for unrelated studies from Sun Pharma (GR is also a consultant) and from Servier. GR confirms that neither of these organisations had any involvement in the present "study" (i.e., review).

The remaining authors declare that the research was conducted in the absence of any commercial or financial relationships that could be construed as a potential conflict of interest.

Copyright (C) 2020 Muniangi-Muhitu, Akalestou, Salem, Misra, Oliver and Rutter. This is an open-access article distributed under the terms of the Creative Commons Attribution License (CC BY). The use, distribution or reproduction in other forums is permitted, provided the original author(s) and the copyright owner(s) are credited and that the original publication in this journal is cited, in accordance with accepted academic practice. No use, distribution or reproduction is permitted which does not comply with these terms. 